\title{
Social and emotional learning through a Teaching Personal and Social Responsibility based after-school program for disengaged middle-school boys.
}

Gordon, B, Jacobs, J. M. \& Wright, P. M. (2016). Social and emotional learning through a Teaching Personal and Social Responsibility based after-school program for disengaged middle-school boys. Journal of Teaching in Physical Education 34(4) 358-369.

\begin{abstract}
This study examined a long-term afterschool leadership program situated in a Midwestern university town in the US. The activity-based program for boys considered to be disengaged with school and at risk for dropping out of education, was based on the Teaching Personal and Social Responsibility (TPSR) model. The program curriculum was strongly aligned with the social and emotional learning (SEL) theoretical framework. The study sought to identify the learning $(s)$ that occurred and the impact of participation for participants.

The key findings were that 1) the pedagogical approach and strategies of TPSR when implemented with a high level of fidelity align strongly with the SEL framework; 2) the structure and design of this TPSR based program was an important ingredient in the school's overall approach to supporting SEL among students, and 3) a number of SEL outcomes were identified as a result of participation in this program.
\end{abstract}


For many people, involvement in sport and physical activity contexts is seen as an effective way of helping participants to become better members of society, an experience that leads to positive socialization and character development (Gould \& Carson, 2008). The belief that participation leads to positive outcomes has resulted in many countries offering after-school sport and activity-based programs for students. This article reports on one such after-school program, "Project Leadership", a club established in a US middle school specifically for 11 to 14 year-old boys perceived to be disengaged with their school and at risk of dropping out of education. While the club used sport and physical activity as a context to attract and engage students, the primary focus was not on developing traditional sporting outcomes but building life skills and developing personal and social responsibility.

\section{Social and emotional learning}

Social and emotional learning refers to the process whereby youth develop knowledge and skills which they can use to interpret and control their emotions, build lasting friendships, develop strong social skills, identify and work towards personal goals, and make healthy choices (CASEL, 2014). SEL is based on five interrelated competencies from the cognitive, behavioral, and emotional domains. These core competencies are self-management, self-awareness, social awareness, relationship skills, and positive decision-making (CASEL, 2014). Researchers posit that deliberate instruction and strategic opportunities to practice these five competencies foster the development of integral skills such as managing emotions, setting goals, and building positive relationships, all of which are deemed to be essential for youth success in school, home, and community life (CASEL, 2014; Durlak, Weissberg, Dymnicki, Taylor, \& Schellinger, 2011; Newman \& Dusenbury, 2015). SEL helps foster student development and increase student-school connectedness, both of which are considered to help promote academic success, prevent problem behaviors, and enhance physical and psychological health (Durlak, et al., 2011; Durlak, Weissberg, \& Pachan, 2010; Elbertson, Brackett, \& Weissberg, 2010).

Social and emotional competence has been identified internationally as an important educational outcome. Jacobs, Knoppers, and Webbc (2013) commented that "Educational policies and curriculum documents in many European countries promote 
the social and moral development of young people as a cross-curriculum goal ... [and that] All subjects, including physical education are required to contribute to the social and moral development of the children" (p.1). The national curriculums of many countries specifically identify components of SEL to be taught across all learning areas. In Australia, these are described as general capabilities and include personal and social competence and ethical behavior (Australian curriculum, assessment and reporting authority, 2013). Singapore includes responsible decision-making, relationship management, social awareness, and self-management as central to their curriculum's emphasis on developing $21^{\text {st }}$ century competencies (Singapore Ministry of Education, 2015) while in New Zealand key competencies including managing self and relating to others are identified to be taught across the curriculum (Ministry of Education, 2007, p. 12). In Scotland, the national curriculum mandates that physical education foster mental, emotional, social and physical well-being, including competencies related to self-awareness, responsible decision-making, and social skills (Scottish Government, 2009, p. 1).

A similar process has occurred in the US where a number of states now require that SEL competencies be taught as part of the general curriculum. Two of the national content standards articulated by the Society for Health and Physical Education (SHAPE, 2015) are directly aligned with SEL. These call for students to "exhibit responsible personal and social behaviors that respect the self and others" (Standard 4) and to "value physical activity for health, enjoyment, challenge, selfexpression and/or social interaction," (Standard 5). SHAPE (2015) also supports SEL stating that SEL programming improves student behavioral and academic outcomes and urges schools to integrate it into their standard curriculum.

Perhaps the most significant indicator of momentum building at the federal level is the Every Student Succeeds Act (ESSA), which was signed into law in 2015. This law redefines the assessment of student success by specifically taking into account the nonacademic factors of student development such as relationship skills, communication, and school engagement ("Every Student Succeeds Act," 2015). The expectation that schools will facilitate SEL means that it is imperative they explore how SEL can best be integrated into school programming, both inside and outside of the classroom.

While in many ways the school classroom is an opportune setting for effective SEL program implementation, the pressure of high stakes testing and the demands of 
meeting curriculum outcomes may restrict the degree to which teachers address SEL with their classes. Afterschool programs have been suggested as another potential context to develop SEL both because there is typically no obligation to teach academic material, and students tend to express high levels of enjoyment and commitment regarding extracurricular activities (Shernoff \& Vandell, 2007). Within both contexts, a potential challenge is identifying effective pedagogical approaches for facilitating SEL. Research on mentoring programs and leadership clubs has demonstrated that some particular instructional methods are effective in promoting the core competencies. Role-playing, peer coaching, conflict resolution, and perspective-taking have all been shown to be effective instructional strategies that develop valuable life skills (Bickmore, 2002; CASEL, 2014; Jones, 2004). Many youth programs that state SEL as an objective have been criticized for not including evidenced-based practices in their programs. Criticism includes that they are plagued by poor management, lack teacher and administration buy-in, and include program development, implementation, and evaluation efforts that don't meet the needs of the student population (Durlak, et al., 2011; Newman \& Dusenbury, 2015). These shortcomings in SEL programming not only short-change students, but also underscore the need for evidence-based delivery methods that promote the optimal conditions for SEL.

\section{Sport and SEL}

Sport and physical activity programs have been proposed as potential contexts for the promotion of certain competencies in the SEL framework (Gould \& Carson, 2008; Papacharisis, Goudas, \& Theodorakis, 2005) with many believing that they are suitable contexts for the development of life skills (Camiré, Forneris, Trudel, \& Bernard, 2011; Danish, Forneris, Hodge, \& Heke, 2004; Ewing, Gano-Overway, Branta, \& Seefeldt, 2002; Fraser-Thomas, Côté, \& Deakin, 2008). These contexts have often been used to promote life skills because of their ability to align SEL with skill acquisition, team-building, and the experiences of winning and losing (Gould \& Carson, 2008; Papacharisis, et al., 2005; Wright, Li, Ding, \& Pickering, 2010). Sport and physical activity also tends to be enjoyable for many adolescents (Csikszentmihalyi, Kleiber, \& Larson, 1984; McCarthy, Jones, \& Clark-Carter, 2008), and this enjoyment can be used to attract participants and to keep them engaged. When these factors are taken together, it seems sport and PA programs in the afterschool context may offer great potential for teaching life skills that relate to SEL. 
While there has been interest in sport and physical activity programs, generally, there has been little examination on the impact on SEL of sport and physical activity programs, particularly when they have been taught using a validated instructional model (Ang, Penney, \& Swabey, 2011; Talebzadeh \& Jarfari, 2012). This study will address this gap by exploring how SEL can be fostered through an afterschool physical activity program based on one such model, the Teaching Personal and Social Responsibility (TPSR) model (Hellison, 2011).

\section{The Teaching Personal and Social Responsibility Model}

TPSR is a widely implemented sport and physical activity based instructional model that offers the opportunity to implement best practices in SEL. A growing number of youth development sport programs have adopted TPSR and the model has been used by practitioners around the world in a number of settings including physical education, community programs, and afterschool sport programs (Lee \& Choi, 2015; Walsh, Veri, \& Willard, 2015; Wright, Jacobs, Ressler, \& Jung, 2016). TPSR promotes social and personal development by shifting the focus of sport away from solely acquiring technical sport skills (e.g. learning to do a volleyball serve) and adding an equal focus on developing personal and social responsibility. It does this to a large degree by explicitly integrating a number of youth development principles into sport lessons (e.g., discussing self-control strategies during a conflict on the volleyball court). According to David Kirk's (2013) concept of Models Based Practice, TPSR is an instructional model because it helps to define preferred practice in terms of teaching and learner engagement. TPSR addresses a discrete set of learning outcomes that have relevance within any activity, unit, curriculum or program plan.

A TPSR-based lesson generally follows a typical format (Table 1). A session begins with informal relational time for students to socialize freely and establish rapport with one another and program coaches. Relational time is followed by a group awareness talk in which coaches and students gather to discuss the group goals for the day and outline what lessons (both sport- and responsibility-based) will be covered. The sport/physical activity content of the class is then delivered using a variety of pedagogical approaches designed to generate learning around personal and social responsibility. These include giving students choices, peer coaching, conflict resolution, and leadership opportunities. The class concludes with a group meeting time where students provide feedback on the lesson and reflect on the goals of the day and their own behavior during the lesson in relation to these goals. This time is also 
used to discuss the transferability of these lessons to their family, school, and community settings (Hellison, 2011).

A TPSR program focuses on students achieving five major goals (levels).

These are described as respect (Level 1), participation and effort (Level 2), selfdirection (Level 3), caring and leadership (Level 4) and transfer (Level 5). These are more fully described in Table 2 .

Table 1

Daily program format for the Teaching Personal and Social Responsibility model

\begin{tabular}{|ll|}
\hline \multicolumn{1}{|c|}{ Class Component } & \multicolumn{1}{c|}{ Description } \\
\hline Relational Time & $\begin{array}{l}\text { Informal social time at beginning of program for students } \\
\text { and coaches to socialize. The purpose of this component } \\
\text { is for students to have the opportunity to establish } \\
\text { meaningful relationships with the coaches. }\end{array}$ \\
Awareness Talk & $\begin{array}{l}\text { A brief coach led talk to introduce the life skills that will } \\
\text { be the focus of the day (e.g., effort, respect, leadership). } \\
\text { A coach led lesson on the chosen sport for the day, } \\
\text { integrated with the life skill discussed during the } \\
\text { Physical Activity }\end{array}$ \\
Lesson & $\begin{array}{l}\text { awareness talk. Significant time allowed for peer } \\
\text { coaching, goal setting, conflict resolution and other } \\
\text { teaching strategies. } \\
\text { A post-activity discussion to evaluate the session. } \\
\text { Students are encouraged to share their thoughts about the } \\
\text { positives and negatives of the session, make suggestions } \\
\text { for future sessions and discuss how the group performed } \\
\text { in both sport and the life skills. } \\
\text { Students are asked to reflect on their own attitudes and } \\
\text { behaviors during the lesson and share these with the } \\
\text { larger group. }\end{array}$ \\
\hline
\end{tabular}

The TPSR model has a number of components that inherently connect to SEL (Table 2). To date, however, no studies in youth development, sport, or SEL have examined the similarities between these two entities. Some literature does describe similarities between TPSR program goals and the specific SEL competencies (Jacobs \& Wright, 2014; Wright, Li, Ding, \& Pickering, 2010), but there has been no discussion around TPSR and the larger SEL framework in these studies.

\section{Implementation Fidelity}

In any study of Models-Based Practice, it is important that the researchers can demonstrate a good level fidelity to the model (Kirk, 2013). The issue of the degree of fidelity that occurs in practical implementations has generated some discussion. 
Curtner-Smith, Hastie, and Kinchin (2008), for example, in their analysis of beginning teachers teaching of sport education found varying degrees of adherence. These ranged from a full "as intended" application, to a watered down version and what the authors described as a "cafeteria approach" that only included select elements. According to Dyson and Casey (2012), it is common for teachers to modify their models-based instruction to suit their preferences. Gordon and Doyle (2015) caution, however, not to automatically dismiss variations to the model as in some cases these variations may be a result of teachers having a strong understanding of the model that enables them to modify their implementation in a way that addresses student needs and context while still carrying out the goals of the model. While some

Table 2

Similarities between the 5 TPSR model levels and the 5 SEL competencies

\begin{tabular}{|c|c|c|c|}
\hline TPSR goals & Description & SEL connection & Research support \\
\hline Respect & $\begin{array}{l}\text { Students are encouraged to } \\
\text { show respect for the feelings } \\
\text { and rights of others while } \\
\text { developing empathy and } \\
\text { understanding of other } \\
\text { viewpoints }\end{array}$ & $\begin{array}{l}\text { Self-awareness, } \\
\text { Social-awareness }\end{array}$ & $\begin{array}{l}\text { Debusk \& Hellison, 1989; } \\
\text { Liu, Karp, \& Davis, 2010; } \\
\text { Debusk \& Hellison, 1989; } \\
\text { Walsh, } 2013\end{array}$ \\
\hline $\begin{array}{l}\text { Participation and } \\
\text { effort }\end{array}$ & $\begin{array}{l}\text { Students are encouraged to } \\
\text { accept and persevere through } \\
\text { challenges and find } \\
\text { meaningful activities to } \\
\text { participate in }\end{array}$ & $\begin{array}{l}\text { Positive decision } \\
\text { making, self- } \\
\text { awareness }\end{array}$ & $\begin{array}{l}\text { Hastie \& Buchanan, 2000; } \\
\text { Holt, Tink, Mandigo, \& } \\
\text { Fox, 2008; } \\
\text { Wright, Li, Ding, \& } \\
\text { Pickerding, } 2010\end{array}$ \\
\hline Self-direction & $\begin{array}{l}\text { Students are challenged to } \\
\text { assume responsibility for } \\
\text { their actions, set goals, and } \\
\text { overcome peer pressures }\end{array}$ & $\begin{array}{l}\text { Self-management, } \\
\text { self-awareness }\end{array}$ & $\begin{array}{l}\text { Escartí, Gutiérrez, } \\
\text { Pascual, \& Marín, 2010; } \\
\text { Martinek \& Lee, } 2012\end{array}$ \\
\hline $\begin{array}{l}\text { Caring and } \\
\text { leadership }\end{array}$ & $\begin{array}{l}\text { Students are taught to } \\
\text { develop interpersonal skills } \\
\text { such as support, concern, and } \\
\text { compassion }\end{array}$ & $\begin{array}{l}\text { Relationship skills, } \\
\text { social awareness }\end{array}$ & $\begin{array}{l}\text { Holt, Tink, Mandigo, \& } \\
\text { Fox, } 2008\end{array}$ \\
\hline Transfer & $\begin{array}{l}\text { Students are taught the value } \\
\text { and relevance of the skills } \\
\text { outside of the gym and } \\
\text { encouraged to apply the } \\
\text { lessons in their own lives. }\end{array}$ & $\begin{array}{l}\text { Positive decision } \\
\text { making, self- } \\
\text { awareness, social } \\
\text { awareness }\end{array}$ & $\begin{array}{l}\text { Martinek \& Lee, 2012; } \\
\text { Walsh, } 2008\end{array}$ \\
\hline
\end{tabular}

flexibility is accepted, it is important to ensure that flexibility does not progress to what Claxton (personal correspondence, 2012) described as a toxic mutation whereby, while the name is retained, the reality of practice varies markedly from the model's 
intentions. From a research perspective, it is also important to ensure that a high degree of fidelity occurs in order to give confidence that identified outcomes can be attributed to the implementation itself. This argument has been made relative to TPSR research as well, with some advocating for the use of customized instruments to document and assess the strength of implementation fidelity (Escarti, Wright, Paschall, \& Gutierrez, 2015; Wright \& Craig, 2011; Wright \& Walsh, in press).

\section{Research questions}

To examine the connections between TPSR implementation and SEL outcomes, this study seeks to answer the following questions:

1. To what degree does a high fidelity implementation of a TPSR based afterschool leadership club generate SEL outcomes for its participants?

2. Was the implementation of the after school leadership club perceived as valuable by the school community?

3. Was the after-school leadership club integrated into school wide approaches to supporting SEL development in students?

\section{Methods}

\section{Program description and participants}

Project Leadership, an afterschool leadership program, was developed as part of a larger partnership between a university and nearby public school. The primary purpose of the program was to teach life skills through sport activities and for the students to apply these skills in their school and community. The program is held at one middle school located in a Midwestern university town and is staffed by a university professor and three university students/coaches. At the time of this study, the school had 644 sixth, seventh, and eighth grade students and a student body consisting of $61 \%$ Caucasian, 19\% Hispanic, $13 \%$ African American, $4 \%$ multi-racial, and $2 \%$ Asian. Forty-eight percent of these students were identified as low-income students.

At the request of the school's administration, the program was created for male students who gained membership through teacher invitation or school staff recommendations based on a routine risk assessment conducted for all students in the middle school. In general, the students who gained entry into the program shared several characteristics that placed them at risk for not graduating high school. These 
included having no stable peer group, stressful home situations, low academic performance, inconsistent school attendance, and high levels of behavioral referrals. Once students were invited to the program, they attended on a voluntary basis. Program participants met biweekly for 75 minutes over the course of two school years (September to May). In the second year of the program, in addition to four returning members, approximately ten to twelve new males were invited to participate. Daily attendance ranged from six to fourteen students which was similar to the numbers attending in the first year.

The university coaches maintained a strong partnership with the school during the program's development, implementation, and evaluation. Through monthly meetings, correspondence, and external observations, program coaches and middle school staff such as the principal, assistant principal, and school social worker collaborated to address the ongoing needs of the students from a social, academic, and behavioral standpoint. The school physical education teacher was not directly involved in the program but was aware of the club and supportive of its goals. She attended a small number of sessions to help the boys make the connection between the club and what they did in physical education. She also attended a small number of the meetings involving the school and the program team focused on addressing individual behavioral issues of the boys.

The university coaches received significant training in sport based youth development principles and the TPSR model from the program director and third author, a professor in the field of Kinesiology with 20 years of experience designing, implementing and evaluating TPSR programs. The second author was a graduate student at the time of this study who assisted with directing and teaching in the program. The first author is a professor from another institution with more than 10 years of experience implementing and studying TPSR.

The program sessions followed the TPSR format (Table One). Each session began in a school classroom where students were given a school-sponsored, healthy snack and provided time to informally interact with coaches and other program members. When snack time concluded, the coaches and students discussed what the focus of the session (i.e., TPSR related goals) was going to be and how the session was to be organized. Once this awareness session was concluded the program moved to one of the school's gymnasiums or outdoor sports fields, depending on space availability. The activity time was structured in ways to give students the opportunity 
to practice and gain greater understanding around personal and social responsibility. Students, for example, were given responsibility for obtaining the necessary sport equipment, fairly splitting up the teams, selecting student-coaches to lead practice drills, and devising a system of rules, including how to work out any conflicts that arose from play. These authentic experiences were then considered in the group discussions held at the conclusion of the lesson in relation to what they had learnt and the applicability of the learning in other areas of their lives.

The use of students to select teams and coaches is a good example of TPSR in practice and of how the leaders intentionally used emotional contexts to facilitate SEL. This practice has been, rightly, heavily criticized because of the emotional damage it can cause for participants (Cardinal, Yan, \& Cardinal, 2013). In this program the leaders chose to use students in these roles. The leaders then talked explicitly about how this process can be embarrassing and exclusionary if handled badly. The students understood this and subsequently made great efforts to ensure teams were selected in appropriate and sensitive ways, including selecting teams in private.

The study participants included the principal, assistant principal and social worker (all Caucasian) from the middle-school, two university students/coaches, and three middle-school student participants. The principal (male) and the assistant principal and social worker (females) had several years of experience working at the school and were recruited based on their role(s) in the school and their ongoing relationship with the program. The two female university students were both research assistants (one Hispanic graduate student and one African American undergraduate) who taught in the program on a regular basis during the time of this study. Three middle-school students, Kobe, Antonio and Lucas (pseudonyms), were interviewed to represent the youth participants' perspective. Among the 14 students that were regular participants (quantified as attending at least once a week for longer than 4 months) these students had regularly attended for the longest duration of time over the two years. This purposeful sample (Sandelowski, 1995) was selected because the program content is cumulative and the students who attended the most were perceived to have the greatest exposure to the content. Two of the boys were 13 years old and one was 14 at the time of the study. Kobe identified as African American, Antonio as Hispanic, and Lucas as Caucasian. Institutional approval was secured for this study 
and all participants gave their consent to participate. Active consent was provided by the students' parents.

\section{Data sources and data collection procedures}

Data collection for this study involved a number of sources including interviews, a TPSR fidelity checklist, and field notes. These data sources and data collection procedures are described in the following sections.

Interviews. Formal interviews were completed with the school principal, assistant principal, social worker, two university coaches, and the three middle-school students. The interviews were semi-structured in nature (Patton, 2002), i.e. they were conversational in tone, but guided by key topics or prompts. An example prompt, with follow up, from a middle-school personnel interview is, "Can you explain your school's approach to promoting social and emotional learning?...Do you see Project Leadership contributing to that mission?...If so, how?". An example of the sequence from a university coach interview is, "Have you seen any of the boys in the program change their behavior in the club?...If so, can you give an example?... What do you think has brought about these changes?". A final example from a middle-school student interview is, "We have been talking about self-control a lot in the club...What do you think self-control means? Can you give an example"? The adult interviews lasted approximately one-hour and were conducted by the first author. The student interviews lasted approximately 30 minutes and were conducted by the second author. All interviews were conducted at the middle-school in an empty office or classroom at a time that was most convenient for the participants. The assistant principal and the social worker were interviewed on two occasions. All other participants were interviewed once.

All interviews were audio-recorded and transcribed verbatim. The transcripts were subsequently entered into NVivo (NVIVO, 2012) software package to facilitate data management and analysis.

TPSR Implementation Checklist. In this study, fidelity was monitored through the systematic use of the TPSR implementation checklist (Wright \& Walsh, in press). The first two sections of the checklist prompt discussion on the degree to which a session has addressed the key underpinnings of the TPSR model. These include the four key components of TPSR implementation, the five responsibility goals/levels 
(Table 2) and the five parts of a typical TPSR lesson (Table 1). The third section lists nine teaching strategies which Wright and Craig (2011) have suggested show high quality responsibility-based instruction. These teaching strategies are described as modeling respectful behavior, setting clear expectations, providing opportunities for success, fostering social interaction, assigning management tasks, promoting leadership, giving choices and voices, involving students in assessment, and addressing the transfer of life skills. The final section describes nine student behaviors that demonstrate an enactment of responsibility. These student behaviors are participating, engaging, showing respect, cooperating, encouraging others, helping others, leading, expressing voice, and asking for help. The working definitions for the teaching strategies and student behaviors were drawn from the Tool for Assessing Responsibility-based Education, (Wright \& Craig, 2011; Wright \& Walsh, in press) a more extensive TPSR fidelity instrument and systematic observation system.

After each lesson, the teaching team assembled to debrief using the checklist as a guide to identify areas of strength and weakness in the implementation of the day's lesson. This process formed the basis for reflection and planning for future sessions. While the checklist was used routinely as a guide for reflection, approximately every other lesson a copy of the checklist was filled out to document implementation fidelity. The formal and informal use of the checklist, allowed the team to deliberate on the degree to which the various aspects of TPSR had been successfully implemented. This process not only documented implementation but continually reinforced for the teaching team the importance of adhering to the TPSR model.

Field notes. Field notes included post-teaching reflections by program coaches that were completed after each lesson. In these post-teaching reflections, the coaches were asked to reiterate what the plan for the lesson had been as well as any modifications to that plan. The coaches were then asked to describe critical incidents (positive or negative) and reflect on their significance. Finally, coaches were encouraged to include any additional thoughts related to TPSR implementation, especially those that were discussed with the team when debriefing on implementation.

In addition to post-teaching reflections, field notes were also used to document the development and administration of the program and the research process. For example, field notes were used to document planning meetings, action items, 
information shared by school administrators, background information related to students. The field notes also recorded informal interviews, conversations and debriefs with the students that occurred as a natural part of the program.

Contextual notes were also taken to describe the school's approach to social and emotional learning as reflected in formal curriculum documents, the school website, program offerings, and signage throughout the school. Team members were also encouraged to document and reflect on barriers and facilitators to running the program, conducting the research process, theoretical linkages, etc.

\section{Data Analysis}

All interviews were audio-recorded and transcribed verbatim. Field notes were either entered electronically or subsequently transcribed. The interview transcripts and field notes were entered into NVivo (Nvivo, 2012) software package for data storage and management. Commentary about implementation checklist debriefs were recorded in field notes and the paper checklists that were completed by the team were also scanned and added to the electronic database. Analysis of the checklists included identifying themes of TPSR components that were consistently demonstrated or excluded from the lessons. Specifically, checklists were used to measure fidelity to the TPSR model by assuring that class format components (e.g., awareness talk, reflection time, etc.) and model levels (e.g., respect, caring, transfer) were being addressed in each lesson. Although all authors had been immersed in the project for an extended period of time, formal data analysis began with all authors reading data sources several times to build familiarity with the data set. Inductive analysis allowed the three major themes to be identified though an iterative process of collapsing, combining, and revising codes until a list of discrete and complimentary codes remained (Braun \& Clarke, 2006). The second author developed the initial coding scheme which was then refined with the other authors using the iterative process described above until consensus was reached. No themes had been identified from the literature prior to the analysis process commencing.

Several steps were taken to ensure the trustworthiness of the data (Lincoln \& Guba, 1985). Triangulation of data sources allowed us to compare different perspectives and different types of evidence in forming interpretations. After all interviews were completed member check involved providing participants with transcripts and having debriefing conversations with them to inquire about any errors or omissions. No such concerns were voiced by any of the participants. Peer 
debriefing was used extensively. The first author was involved in the project primarily as a researcher while the other authors had also been involved in designing and delivering the program. This allowed the team to view the data from different perspectives, i.e. insider and outsider. In addition to regular debriefing sessions during research meetings, the first author also conducted formal peer-debriefing interviews with the other two authors and used this information to test assumptions, search for disconfirming evidence as a way to confirm the completeness and accuracy of the findings as well as the consistency of interpretations. The last stage in the process involved all members of the team reviewing and analyzing the data set once more to ensure no important themes had been missed and to identify sections of raw data that would be useful in characterizing the various themes in this narrative.

\section{Findings}

This study was interested in identifying the degree to which the TPSR-based pedagogical approaches and strategies, used in the reality of the leadership club, aligned with the theoretical framework of SEL. It was therefore necessary to confirm that the way the leadership club was implemented demonstrated a high level of fidelity to the TPSR model. The implementation checklists, reflective diaries and field notes all give confidence that a consistently high fidelity implementation occurred. The implementation checklists showed a consistent following of the TPSR program format and integration of the four major themes.

The coaches also regularly used validated teaching strategies such as giving choices and voices, promoting leadership, and talking about transfer of life skills outside of the program setting. This commitment to the central tenets of TPSR established a strong framework in which to examine the degree of alignment with SEL.

The findings are presented under the following three themes: The relationship between the TPSR-based approaches and strategies used in the leadership club and the SEL framework; the school's view of the TPSR based program and its role in supporting an overall approach to SEL; and the generation of SEL outcomes in student participants.

The relationship between the TPSR-based approaches and strategies used in the leadership club and the SEL framework 
When examining this relationship between the TPSR-based approaches and strategies used in the leadership club and the SEL framework it was found that strong similarities existed (Table 2). There are some differences in the language used by TPSR and SEL but the degree of overlap in the terms meant that at a practical level this was largely irrelevant for the students. Self-control, for example, is a major goal for TPSR and is also an aspect of self-management, an important component of SEL. In the reality of the day-to-day coaching the coaches and the students used the words self-control but all also understood that using self-control was part of managing themselves.

An example of how the practical activities were used as a strong emotional context to develop understanding of self-control/self-management was recorded in the field notes. It occurred during the group discussion towards the end of a session that involved a particularly vigorous game of dodge ball. The issue under discussion was self-control and students were asked if anyone had lost self-control during the game. One boy responded that he had when he had been hit in the head by a ball while on the ground. The coach commented that he hadn't noticed him losing control of himself:

Student ... I did lose control but I kept in my brain

Coach ... So that is what we mean when we talk about self-control.

When you don't act out but keep it in your brain so you don't get into trouble

This conversation was followed by a long silence from the boys who were deep in thought and then by a spontaneous round of applause.

The study was interested in establishing the degree to which the various elements of the daily program format facilitated development of the five SEL competencies, and how their implementation in practice aligned with best practice as identified in the literature. The following section will be presented under the headings of the TPSR program components.

The awareness talk. Having clearly defined goals in youth programs is crucial in effectively facilitating SEL. Durlak et al. (2010), for example, describe the important of program leaders being explicit about what SEL skills are being addressed (e.g., self management, relationship building). The TPSR model's "awareness talk" component is consistent with this concept and extends the idea by encouraging coaches to connect program goals to the specific curriculum content presented for 
each class. An awareness talk was evidenced in nearly every coach reflection entry with many examples of explicit goal-setting noted. One coach wrote: "I told the boys, today we are going to play basketball and asked them 'so what types of things are needed to play team sports?' The boys came up with many good answers that reflected directly back to the [TPSR] model including "not getting mad when we don't win (self-control), helping your teammates (caring), and being a good sport" (respect).

The physical activity component. Recommendations from several program studies support emphasizing active forms of learning to help promote SEL competencies. In the TPSR model, the integration of learning around TPSR related goals with the physical activity component is one of four underpinning themes. Perhaps unsurprisingly, the efficacy of this approach was frequently supported in the coaches' field notes. One coach described how a physical activity lesson related to trust actually changed a student's perception about his partner's trustworthiness: 'Nick mentioned how he didn't trust his partner during the activity, but after the trust walk he said he felt more confident since he had successfully led him through the entire [obstacle] course."

Group meeting and reflection time. One specific goal of the SEL framework is for students to build self-awareness through recognizing their emotions, strengths, and weaknesses. Inherent in the TPSR lesson format is a "group meeting" and "reflection time" (Hellison, 2011). This time is used to discuss the day's session and to encourage participants to self-reflect. One coach wrote: "Today I had everyone go around in the circle and say one word to describe their behavior last class (they were ALL negative) and then go around again and describe one word from their behavior in this class (they were ALL positive)." This is not only an example of giving students a voice but doing it in the context of self-reflection. The coach continued, "Then I gave all the credit to [the students] for turning their behavior around and making something good come from the challenge." In this instance, the coach demonstrated how an effective self-awareness talk can lead to experiences of empowerment and self-awareness for the students.

Self-awareness, or challenging students to reflect on their strengths and weaknesses was emphasized throughout the group meeting and reflection times. One coach wrote of an instance where a student disclosed his weakness to the group: "during our reflection time [Lucas] said he thought he should work on his focus 
because he was a little distracted with stuff on his mind, a very mature and insightful thing to say for a thirteen year old." Another coach described a challenging day in the program: "I gave everyone the opportunity to tell me about their behavior for the day and offer up any words of apology to [Coach] and [Coach]. The boys really took ownership and talked about their lack of focus, disrespect, and overall sluggishness and apologized to [the coaches]."

When the five key components of SEL are considered it became clear that all were addressed on a regular basis in the program. The data is rich in examples of practices and activities developing self-management, self -awareness, social awareness, relationship skills, and positive decision making through the TPSR model. These ranged from the boys choosing the program of activities to making decisions around teams and rules.

In considering the relationship between the TPSR and SEL, the data would support the conclusion that the TPSR-based approaches and strategies used in the program were closely aligned with a SEL framework.

\section{The school's view of the TPSR based program and its role in supporting their overall approach to SEL}

The school was unreserved in it valuing of the leadership club. This is perhaps best exemplified by the comments of the school administrators about how they would like to see the leadership club develop into the future. All hoped for a continuation of the program and for its extension either within the school or into the wider community. Both the Principal and Associate Principal felt strongly that the club's success meant that it should be extended into high school to allow continuity for the boys. As the principal stated:

There is no reason that it needs to stop in the eighth grade if we are seeing, if the outcomes are showing that it's a positive thing and its preventing kids getting in trouble or getting connections they didn't have before, but I feel like it's a no brainer that we need to continue that [the club] in high school The study was interested in seeing whether, and if so how, the leadership program supported SEL initiatives already established in the school. One unexpected finding was that the club had impacted on a number of school-wide policy and practices. The Assistant Principal explained:

It's interesting because I think that the formation of this group in our school has made us look at how we do everything that we do in the school and 
looking at how we even process kids for disciplinary reasons and how teachers process with kids. I think that being involved in this program and the formation and talking about what we are trying to teach these kids... we are saying here are the core values of what we want to teach to teach these kids and then it makes us reflect well is this how we are doing business... If we are putting resources into helping kids develop social responsibility and being personally responsible for what they do are we building a system around them that helps them to do that? ... And so I think its led to some good conversations with our staff - service team and our social worker and our counselors and our administration.

This was an interesting viewpoint in that rather than seeing the leadership club simply as a support for the school wide approaches towards SEL, the leadership club had been influential in how relationships in general within the school were conceptualized and implemented.

\section{The generation of SEL outcomes in student participants}

The data, from a variety of sources, would support that some students involved in the club took onboard many of the SEL outcomes. One example, given by the assistant principal, concerned Kobe, a second year attendee whose explosive temper had previously been problematic within the class environment. As a result he had been a regular visitor to her office for disciplinary reasons the previous year.

I don't know if he has had anyone give him the concrete feedback [that he received in the club] that if you are going to be a leader and you don't get your own way and you explode then no one is going to listen to you ... and I haven't seen him in the office for disciplinary reasons once this year yet. Self-awareness. In their interviews the students were also able to offer insight into their own social and emotional development. Lucas demonstrated increasing selfawareness when he discussed the importance of the program goal of respect at home, particularly "when I'm expressing how I'm feeling at the moment cause sometimes when I speak, things come across a lot differently than what I meant.” Antonio also exhibited self-awareness when he acknowledged how his level of confidence had changed as a result of this program. "I'm not nervous anymore about being in this club, but I remember the first day of the club I was really nervous because I didn't know any of the people other than Kobe." Later, he described how his self-confidence has grown in the program through trying a new sport: "It was actually my first time 
ever playing football. I never even played football or even knew how to. And I was actually really good- they called me MVP."

Social awareness. While less common than other SEL competencies, instances of social-awareness whereby students demonstrated understanding of other people's perspectives were mentioned in a number of interviews. Lucas articulated the frequent annoyance he felt with his younger brother at home but shared his willingness to see it from another point of view: "a lot of the time I just try to realize how sometimes he really doesn't know that what he's doing is making me really mad, so I definitely think about that and that helps." Antonio echoed this awareness when describing how the bad behavior of a group of new boys who joined the program tended to change throughout the program session. He explained: "usually when [the new boys] stop messing around that means that they are having fun, and they usually messed around a lot in the beginning, but once we get to the sports part, their attitude changes and they do good." Kobe described an instance where he displayed empathy while at a store in looking around for "someone who needs help with something." He continued: "I saw Ms. [name] my $7^{\text {th }}$ grade teacher, and she needed help because she had her kids with her so I helped her." In this simple example Kobe demonstrated how his social awareness and willingness to assist someone in need enabled him to do good for others.

Self-management. The strongest connection between SEL competencies and the reflections of the students was related to self-management, particularly around self-control. In response to a question about when he used lessons from the program at home, Kobe responded, “At home, like, when my brother and sister, they didn't let me join their game... I was angry but just let it go." He later articulated how he deals with anger saying, "If I don't have self-control I'll just let all my anger get to my emotions. Then everyone will get mad at me and I probably won't have any friends." Antonio's comments about self-control were made in reference to the program setting and how self-management during a session makes for a more positive class. He remarked: "If we're messing around and getting hurt it's all gonna be blamed on the school ... when everyone is calm and listening and behaving, we actually have more fun ". He also articulated that the program had impacted his ability to meet his goals in life, another pillar of self-management. He discussed how the program has taught him that if he continues to be a leader he will be able to achieve his life goals, for example, "join the marines when I'm 17 and then get them to pay me so I can be the 
first person in my family to go to college." Lucas commented on his growing understanding of self-control and its application in the academic domain when he stated: "Working with other people can always be a bit of a challenge but when there's not always the person you most want to be with. They can get on your nerves a little bit, and it also works the other way around, you have to make sure you're not doing the same thing to them." Here he combines a self-management statement with a statement that reflects self-awareness.

Relationship skills. Establishing healthy and rewarding relationships is another SEL competency that was observed in the program. All three students interviewed supported the idea that a major benefit of their program involvement was the facilitation of positive peer connections and the opportunity to make friends with people they wouldn't normally be exposed to at school. Several statements clearly illustrate this concept. Kobe, for example, felt that a direct result of the program was establishing new friendships: "Last year when I wasn't in this club I never knew or saw Jamal and Antonio. When we were in the club I started to know them." Antonio shared in this experience of making new friends: "Oh, Johnny, he's one of my best, 'bestest' friends and I found out he lives right next to me. Like seven houses away and we're really good friends now but if it wasn't for this club I most likely wouldn't know him." Lucas was a prime example of a student who struggled with relationship skills and making new friends who commented that, "It's not so bad working with other people in [this program], even when it can be frustrating sometimes."

Positive decision-making. Many reflections about positive decision making involved resisting problem behaviors such as fighting outside of the program. Antonio admitted that when he's tempted to fight someone who is out of line, "Usually I'll think about in my head like what the consequences are if I got into a fight." Kobe echoed this concept by describing how the program helped him stand up to another student in the program and urge him to avoid physical violence "Yeah we motivated Nick not to like, fight back and just tell the teacher instead." Resisting negative peer pressure is another example of making respectful choices. When asked about how the program helps with decisions outside of school, Antonio shared an event where he turned down the offer of marijuana at a party with some older students from school: "They asked me if I wanted some. I said no. They asked me again. They 
kept trying to get me to do it and I said no." This statement illustrates a strong transfer of the program value of positive decision making to a real life context.

The student interviews demonstrated that the leadership programs had facilitated SEL in a way that was impacting their behaviors and the way they related to others in their lives. The school administrators and coaches all reported that they had observed similar outcomes. All of the staff interviewed felt that in general terms participants were improving and showing differing degrees of increased social and emotional competency. The principal commented that "we can all anecdotally say certain things about kids behavior improving in their classes" while the assistant principal agreed and gave a specific example of a poorly behaved student from the club who had improved greatly:

His whole in dealing with staff and being able to ... you know he was a kid that we would see a lot of shutdowns so if he was challenged with even a small behavior it would spiral into something big and he would shut down and his ability to now verbalize and communicate with staff and express this is why I am was frustrated or this is why I didn't do it [has improved].

The school social worker commented that in regards to self-control 'I've seen it (improvement) in the group and I've seen it in the classroom" but she was less certain if it could be attributed directly to the program. "I don't know if it's the group that's doing it or if he's growing up. I'm not quite sure what the link is there".

\section{Discussion}

This study examined an afterschool TPSR based leadership club through the lens of SEL. It sought to identify the learning(s) that occurred and the impact of participation on the participants. SEL was selected as the lens in which to examine this program in recognition of its importance both in positive youth development (CASEL, 2014; Durlak, et al., 2011) and its identification as an important educational outcome in international educational curricula (e.g. Ministry of Education, Singapore 2016, SHAPE, 2015). The study recognized that while there is an interest in sport and physical activity programs being used to facilitate SEL there has been little empirical examination of this relationship, particularly in relation to the use of validated instructional models (Ang, et al., 2011; Talebzadeh \& Jarfari, 2012). TPSR, as an 
instructional model, provides a set of preferred practices (Kirk, 2013) that have been developed to address a set of learning outcomes (i.e. personal and social responsibility) that are explicitly identified in the national standards for physical education and highly relevant to SEL. A number of writers have concluded that in any research based on instructional models being used in practice it is important to demonstrate that a high level of fidelity to the model was established and maintained (Curtner-Smith, et al., 2008; Kirk, 2013). This study used a number data sources to establish that the leadership club had a high level of fidelity to the TPSR model (Hellison, 2011).

The main findings of this study were that:

- a high fidelity TPSR implementation was able to successfully foster SEL in boys that attended regularly.

- the TPSR based approaches and strategies used in the programme were closely aligned with a SEL framework.

- the school administrators were positive about the impact of the club and indicated they would like to see it continued and if possible expanded in the future.

- the leadership club impacted on the school's policies and practices on how they related to students across the school.

- the boys in the leadership club perceived that the program fostered opportunities to develop and practice SEL principles

There are some limitations that need to be acknowledged. Because the club was voluntary some boys only attended on occasions while others dropped out of the program. The impact of participation on these boys is therefore unknown. The project director is an acknowledged international expert on TPSR and his students were well prepared and knowledgeable of the model. This level of knowledge, while not essential in order to successfully implement high fidelity programs, may not be immediately available for many who attempt to implement TPSR based programs and this may have an impact on the SEL of participants. The relationship between the degree of fidelity to the model and subsequent SEL related outcomes is uncertain. This is an area suitable for further research. 
The transfer of learning (TOL) from the leadership club to other areas of the students' lives was not a specific focus of this study. TOL from the club to other areas of the boys' lives was, however, observed by the school administrators and perhaps more importantly was identified through a number of comments made by the boys themselves. TOL is an important component of TPSR having being identified as one of the five goals and four underpinning themes (Hellison, 2011). Despite the importance of TOL the specific aspects of the program that best generated TOL and the degree to which TOL occurred is uncertain. A more precise understanding of how students connect in-program learning to thinking about their behavior outside the program setting is necessary. Gordon and Doyle (2015) summarized the position as being one in which "The research findings [on TPSR and TOL] are mixed both in the commitment to transfer of learning and the level of success that has been achieved" (p. 152). The strong indication from this study that for some of the boys transfer of learning occurred supports the belief that high fidelity implementations of TPSR can generate this important outcome. This is an important area and future studies should examine the issue directly and with more precision.

The findings from this study should be considered within the context of the international trend towards incorporating SEL into school curricula. While the importance of SEL is acknowledged, in many cases what is missing is the confidence that there is a reliable means of converting policy intentions into successful facilitation. This study presents evidence that supports the belief that a high fidelity TPSR based physical activity program can successfully facilitate SEL in participants who attend regularly. This offers support to schools and clubs wishing to generate SEL through sport and physical activity contexts, giving them a degree of confidence that this model can do so successfully. Finally, this study contributes to the literature on models-based practice in physical education (Kirk, 2013) by providing a detailed description and analysis of the implementation of TPSR, a prominent instructional model in the field.

\section{References}

Ang, S. C., Penney, D., \& Swabey, K. (2011). Pursuing social and emotional learning outcomes through sport education. In P. Hastie (Ed.), Sport Education: International Perspectives (pp. 116-132). 
Australian curriculum, assessment and reporting authority. (2013). from http://www.australiancurriculum.edu.au/generalcapabilities/pdf/overview

Bickmore, K. (2002). Peer mediation training and program implementation in elementary schools: Research results. Conflict Resolution Quarterly, 20(2), 137-160.

Braun, V., \& Clarke, V. (2006). Using thematic analysis in psychology. Qualitative reseach in Psychology, 3(2), 77-100.

Camiré, M., Forneris, T., Trudel, P., \& Bernard, D. (2011). Strategies for helping coaches facilitate positive youth development through sport. Journal of sport psychology in action, 2(2), 92-99.

Cardinal, B. J., Yan, Z., \& Cardinal, M. K. (2013). Negative experiences in physical education and sport: How much do they affect physical activity participation later in life? Journal of Physical Education, Recreation \& Dance, 84(3), 4953.

CASEL. (2014). What is social and emotional learning Retrieved 5/17/15, from https://casel.squarespace.com/social-and-emotional-learning

Csikszentmihalyi, M., Kleiber, D., \& Larson, R. (1984). Variations of experience in formal and informal sport. . Research Quarterly for Exercise and Sport, 55(2), 109-116., 5(2), 109-116.

Curtner-Smith, M. D., Hastie, P. A., \& Kinchin, G. D. (2008). Influence of occupational socialization on beginning teachers' interpretation and delivery of sport education. Sport, Education and Society, 13(1), 97-117.

Danish, S., Forneris, T., Hodge, K., \& Heke, I. (2004). Enhancing youth development through sport. World Leisure Journal, 46(3), 38-49.

Durlak, J. A., Weissberg, R. P., Dymnicki, A. B., Taylor, R. D., \& Schellinger, K. B. (2011). The impact of enhancing students' social and emotional learning: A meta-analysis of school-based universal interventions. Child development, 82(1), 405-432.

Durlak, J. A., Weissberg, R. P., \& Pachan, M. (2010). A meta-analysis of after-school programs that seek to promote personal and social skills in children and adolescents. American journal of community psychology, 45(3-4), 294-309.

Dyson, B., \& Casey, A. (2012). Cooperative learning in physical education: A research based approach. : Routledge.

Elbertson, N. A., Brackett, M., \& Weissberg, R. P. (2010). School-based social and emotional learning (SEL) programming: Current perspectives Second international handbook of educational change (pp. 1017-1032). Netherlands.: Springer.

Escarti, A., Wright, P., Paschall, C., \& Gutierrez, M. (2015). Tool for assessing responsibility-based education (TARE). 2.0: Instrument revisions, inter-rater reliability and correlations between observed teaching strategies and student behaviors. Universal Journal of Psychology, 3(2), 55-63. doi: 10.13189/ujp.2015.030205

Every Student Succeeds Act, (2015).

Ewing, M. E., Gano-Overway, L. A., Branta, C. F., \& Seefeldt, V. D. (2002). The role of sports in youth development. Paradoxes of youth and sport, 31-47.

Fraser-Thomas, J., Côté, J., \& Deakin, J. (2008). Understanding dropout and prolonged engagement in adolescent competitive sport. Psychology of Sport and Exercise, 9(5), 645-662.

Gordon, B., \& Doyle, S. (2015). Teaching personal and social responsibility and transfer of learning: opportunities and chalenges for teachers and coaches. 
Journal of Teaching in Physical Education, 34, 152-161. doi: http://dx.doi.org/10.1123/itpe.2013-0184

Gould, D., \& Carson, S. (2008). Life skills development through sport: Current status and further directions. International Review of Sport and Exercise Psychology, $1(1), 58=68$.

Hellison, D. (2011). Teaching personal and social responsibilty through physical education (3rd ed.). Champaign:IL: Human Kinetics.

Jacobs, F., Knoppers, A., \& Webbc, L. (2013). Making sense of teaching social and moral skills in physical education Physical Education and Sport Pedagogy, 18(1), 1-14. doi: DOI:10.1080/17408989.2011.621118

Jacobs, J., \& Wright, P. (2014). Social and Emotional Learning Policies and Physical Education: Column Editor: K. Andrew R. Richards. Strategies, 27(6), 42-44.

Jones, T. (2004). Conflict resolution education:The field, the findings, and the future. Conflict Resolution Quarterly, 22(1-2), 973-986.

Kirk, D. (2013). Educational value and models-based practice in physical education. Educational Philosophy and Theory, 45(9), 973-986.

Lee, O., \& Choi, E. (2015). The influence of professional development on teachers implementation of the Teaching Personal and Social Responsibility model. Journal of Teaching in Physical Education, 34(4).

Lincoln, Y. S., \& Guba, E. (1985) Naturalistic Inquiry. Newbury Park, CA: Sage.

McCarthy, P. J., Jones, M. V., \& Clark-Carter, D. (2008). Understanding enjoyment in youth sport: A developmental perspective. Psychology of Sport and Exercise, 9(2), 142-156.

Ministry of Education. (2007). The New Zealand Curriculum. Wellington: Learning Media.

Newman, J., \& Dusenbury, L. (2015). Social and emotional learning(SEL): A framework for for academic,social and emotional success Prevention science in school settings (pp. 287-306). New York: Springer.

NVIVO. (2012). Qualitative solutions and research. Southport, UK: QSR.

Papacharisis, V., Goudas, M., \& Theodorakis, Y. (2005). The effectiveness of teaching a life skills program in a sport contect. Jounal of Applied Sport Psychology, 17(3), 247-254.

Patton, M. (2002). Qualitative Research \& Evaluation Methods (3rd ed.). Thousand Oaks: Sage.

Sandelowski, M. (1995). Sample size in qualitative research. Research in nursing \& health, 18(2), 179-183.

Scottish Government. (2009). Curriculum for excellence: health and wellbeing: experiences and outcomes.: . Edinburgh: Scottish Government.

Shernoff, D., \& Vandell, D. (2007). Engagement in after-school program activities: Quality of experience from the perspective of participants. Journal of Youth and Adolescence, 36(7), 891-903.

Singapore Ministry of Education. (2015). Values at the core of the 21st Century competencies, from http://www.moe.gov.sg/.../21st-century-competenciesannex-a-to-c.pdf

Society of Health and Physical Educators America. (2015). National standards and grade-level outcomes for K-12 physical education. Chapaigh, IL: Human Kinetics.

Talebzadeh, F., \& Jarfari, P. (2012). How sport and art can be effective in the fields of social, cognitive and emotional learning. Procedia-Social and behavioural Sciences, 47(891-903). 
Walsh, D., Veri, M., \& Willard, J. (2015). Kinesiology career club: Undergraduate student mentors' perspectives on a physical activity-based Teaching Personal and Social Responsibility program. Physical Educator, 72(2), 3017.

Wright, P., \& Craig, M. (2011). Tool for Assessing Responsibility-Based Education (TARE): Instrument Development, Content Validity, and Inter-Rater Reliability. Measurement in Physical Education and Exercise Science, 15(3), 204-219.

Wright, P., Jacobs, J., Ressler, J. D., \& Jung, J. (2016). Teaching for transformative educational experience in a sport for development program. Sport, Educatiion and Society, 21(4), 531-548.

Wright, P., Li, W., Ding, S., \& Pickering, M. (2010). Integrating a personal and social responsibility program into a wellness course for urban high school students: Assessing implementation and educational outcomes. Sport, Education and Society, 15(3), 277-298.

Wright, P., \& Walsh, D. (in press). Teaching Personal and Social Responsibility. In W. Li, M. Wang, P. Ward \& S. Sutherland (Eds.), Curricular/instructional models for secondary physical education: Theory and practice. Beijing:China: Higher Education.

Wright, P. M. \& Walsh, D. (in press). Teaching Personal and Social Responsibility. In W. Li, M. Wang, P. Ward and S. Sutherland (Ed.s). Curricular/instructional models for secondary physical education: Theory and practice. Higher Education Publisher, Beijing, China. 